\title{
Análisis al discurso sobre la política nacional de vivienda en Venezuela*
}

\author{
Salcedo A., Héctor J.** \\ Molero de Cabeza, Lourdes***
}

** Sociólogo. Investigador adscrito al Centro de Estudios de la Empresa, Facultad de Ciencias Económicas y Sociales de la Universidad del Zulia (Venezuela). E-mail:

\section{Salcedoahj@hotmail.com}

*** Doctora en lingüística. Profesora titular, adscrita al Departamento de Ciencias Humanas de la Facultad Experimental de Ciencias de la Universidad del Zulia (Venezuela). E-mail: lourdes molero2001@yahoo.com

\section{Resumen}

El trabajo presenta los resultados del análisis de un documento denominado "Política Nacional de Vivienda y Ley de Política Habitacional", publicado por el Consejo Nacional de la Vivienda en el año 2000. El análisis del discurso se basó en los postulados teóricos de Van Dijk (1998), de Charaudeau (1992) y en los resultados de diferentes investigaciones de Molero (1998, 2001, 2002). Metodológicamente se abordó el nivel referencial, el lógico conceptual y el del discurso, alcanzando una interpretación bajo el enfoque semánticopragmático. El análisis permitió observar cómo el discurso de algunos organismos públicos venezolanos construye su imagen institucional con una valoración positiva y cómo representa las políticas de los gobiernos anteriores con una imagen negativa. El discurso se basa en un esquema binario que contrapone lo viejo (los cuarenta años de bipartidismo) y lo nuevo (el gobierno electo en 1998), lo cual permite constatar por otra parte, que los mensajes del presidente Hugo Chávez han marcado los discursos institucionales del estado venezolano, desde su llegada al poder.

Palabras clave: Política de vivienda, Estado, análisis del discurso, semántica, pragmática.

\section{An Analysis of the Discourse of National Housing Policy in Venezuela}

\begin{abstract}
This paper presents the results of the analysis of a document on The National Housing Policy and The Housing Policy Law, published by the National Housing Council in the year
\end{abstract}


2000. The analysis of discourse was based on the theoretical postulates of Van Dijk (1998), and Charaudeau (1992) and on the results of different research findings made by Molero (1985, 1998, 2001, 2002). Methodologically the referential level, the logicalconceptual level, and the discourse level were approached, permitting an interpretation based on the semantic-pragmatic focus. The analysis showed how the discourse of some Venezuelan public organisms build their institutional image with positive values, and how they represent the policies of previous governments negatively. The discourse is based on a binary scheme that opposes the old policy (the forty years of bipartisanship) and promotes the new policy (the government elected in 1998), which affirms the verification that the discourse of President Hugo Chávez has patterned institutional discourse of the Venezuelan state, since his risel to power.

Key words: Housing policy, state, discourse analysis, semantics, pragmatics.

Recibido: 03-04-08. Aceptado: 03-07-30

\section{I ntroducción}

En Venezuela la problemática de la vivienda constituye uno de los problemas sociales que aparece como insoluble ante los ojos del Estado venezolano. El Estado como uno de los actores sociales principales ha diseñado e instrumentado políticas habitacionales en las últimas décadas, y, sin embargo, el déficit de vivienda ha crecido anualmente. En el estado Zulia, por ejemplo, el déficit de vivienda para el año de 1991 era de 125.113 y para el 1998 era de 230.360 (CONZUPLAN, 2000).

La ineficacia estatal en la solución de la problemática de la vivienda es reconocida por el propio Estado, sobre todo cuando se produce un cambio de gobierno, por lo regular, en Venezuela los nuevos gobiernos comienzan construyendo un discurso institucional que descalifica y presenta en términos negativos la política del gobierno anterior.

En Venezuela, como resultado de las elecciones presidenciales efectuadas en 1998, se instala en el país un nuevo gobierno democrático encabezado por Hugo Chávez Frías. El partido base del nuevo presidente es el Movimiento Quinta República (MVR), que presidió una coalición política denominada Polo Patriótico. El nuevo gobierno desplazó del poder político a los ya tradicionales AD, COPEI y Convergencia. Esto conduce a suponer, en consecuencia, que se da lugar a una nueva concepción de la política en todas sus dimensiones.

Por tal motivo, el propósito de este trabajo consiste en analizar bajo la perspectiva 
semántica y pragmática un documento denominado "Política Nacional de Vivienda y Ley de Política Habitacional"토, producido durante el gobierno de Hugo Chávez Frías. Se intenta realizar un análisis que contemple un recorrido por los niveles referencial, lingüístico y discursivo, con el fin de determinar los esquemas subyacentes implícitos, así como las relaciones entre el contenido del documento y las variables contextuales que rodearon la aparición del mismo.

\section{Fundamentación teórico-metodológica}

El desarrollo del trabajo se fundamentó en los postulados teóricos del análisis del discurso de Van Dijk (1998, 1999), en lo referente a los componentes semántico y pragmático; asimismo, para el estudio del modo de organización discursivo se siguieron los principios expuestos por Charaudeau (1992), especialmente en el análisis de la relación argumentativa. Los postulados de Pottier (1993) sirvieron de base para caracterizar el discurso político-institucional en los niveles referencial, lógico-conceptual y lingüístico.

Se utilizaron además, los referentes metodológicos y los resultados de algunas investigaciones en otros tipos de discursos (Molero, 1985, 1998, 2001, 2002). El corpus o muestra objeto del trabajo fue el documento denominado "Política Nacional de Vivienda y Ley de Política Habitacional" del gobierno de Hugo Chávez Frías, elaborado en el año 2000 y emanado del Consejo Nacional de la Vivienda. En este discurso se seleccionaron los apartados referidos específicamente a la antigua política de vivienda de gobiernos anteriores y a la nueva política diseñada en el gobierno del presidente Hugo Chávez.

En la línea de investigación seleccionada, se analiza el aspecto semántico de cada discurso (componente semántico) y el sentido que éste adquiere cuando se considera su contexto e interlocutores respectivos (componente pragmático), en este caso, en particular, el momento social y político en el cual hace su aparición el documento, las instituciones que componen el sector público social de vivienda y el Estado como un todo.

En el nivel referencial del discurso se analiza cómo se presenta el emisor institucional, cómo construye la imagen del "otro" y cuáles son los referentes, hechos o eventos de la realidad socio-económica a partir de los cuales se elabora el discurso de la política pública de vivienda. Además, se analiza cómo se va estructurando el significado en los distintos niveles del texto desde las microestructuras hasta la macroestructura, la cual define el significado como un todo único. En el nivel lógico-conceptual se estudia el acto de representación mental de lo conceptualizado en el proceso que realiza el sujeto para transformar las percepciones en signos lingüísticos y, de esta manera, emitir 
posteriormente el discurso (mensajes). A su vez, se analiza cuál es el propósito o intención que tiene el emisor en su comunicación y cómo se conciben el sujeto emisor y el "otro", en el proceso de comunicación de acuerdo con el estatuto que asumen los eventos, así como los procesos y causas de los mismos.

En el nivel lingüístico se estudia el léxico (las lexías o términos) empleado para expresar el propósito conceptualizado. Y finalmente, en el discurso se analizan los modos de organización bajo las premisas de Charaudeau (1992) y las estrategias discursivas que emplea el emisor institucional para lograr su objetivo.

\section{Resultados del análisis}

\subsection{Nivel referencial}

En el discurso institucional, en su estructura interna se advierte la presencia de varios actores sociales: la población de bajos ingresos económicos, la cual ha permanecido al margen de la antigua política de vivienda a pesar de ser formalmente a quien va dirigida; las capas medias que son quienes se han beneficiado de las antiguas políticas de vivienda, las instituciones públicas que componen el sector público social de vivienda y el Estado venezolano, como un todo.

El discurso construido por el Estado se califica a sí mismo como viejo y nuevo Estado. El nuevo Estado se autorrepresenta como comprometido con el pueblo y solidario con los intereses y necesidades del pueblo. El viejo Estado venezolano se califica o presenta como el actante que abandonó al pueblo -a la población de bajos recursos económicos-, conduciéndolo a la construcción de barrios constituidos por ranchos y a vivir en condiciones negativas.

El discurso se construye partiendo de la vieja política de vivienda y las condiciones de vida existentes en la población de bajos ingresos económicos; de las limitadas posibilidades que ofrece la ley de política habitacional; del déficit de vivienda o deuda social que tiene el Estado venezolano con los que llama "compatriotas"; de la ausencia de coordinación interinstitucional por parte de los organismos públicos que componen el sector público social de vivienda y de la ausencia de participación ciudadana en los asuntos inherentes al problema de la vivienda. Todos estos aspectos constituyen el referente, hechos o eventos de la realidad socio-económica venezolana, que sirven de anclaje al discurso sobre la política habitacional.

\subsection{Tópicos y macroestructura}


El propósito de esta primera parte del análisis es identificar los núcleos de significado fundamentales del documento a analizar. En líneas generales, el contenido del discurso se puede considerar normal en Venezuela, porque es práctica política e institucional en el país que los nuevos gobiernos que se instalan en el poder comienzan auto-presentándose como los salvadores de la patria, subestimando toda la acción anterior y calificándola en sentido negativo.

El discurso se basa en cinco tópicos: la vieja política de vivienda, la ley de política habitacional, la nueva política de vivienda, la coordinación interinstitucional en materia de vivienda y la participación ciudadana.

En la construcción del discurso el emisor institucional -que en este caso es el Consejo Nacional de la Vivienda-, elabora una representación semántica que se corresponde con una macroestructura que revela el análisis, la cual cumple la función de “...reducir, organizar e integrar la información semántica relevante..." (Molero, 1985: 40). Según esta autora, la macroestructura sintetiza como un todo e integra jerárquicamente los diversos significados que contienen o expresan las oraciones de una secuencia (Molero, 1985). En este sentido, como se observa en el Gráfico 1 sobre tópicos y macroestructura, la representación semántica del discurso institucional recoge la idea clave del documento analizado: "La nueva política de vivienda del Estado venezolano, durante el período de gobierno de Hugo Chávez Frías, garantiza la solución del problema habitacional". Así se resume el propósito primordial del discurso o representación semántica descubierta en el análisis. Del gráfico se desprende también que el discurso construido es coherente debido a que los cinco tópicos que lo componen pueden ser incluidos en la macroestructura que contiene la idea clave de todo el documento. Así como las frases componentes (microestructuras) de cada tema pueden ser incluidas perfectamente en el tópico respectivo. Esta relación de inclusión es lo que define la coherencia de un discurso (Molero, 1985), pudiéndose afirmar, en consecuencia, que el documento analizado cumple con este rasgo de la textualidad. 


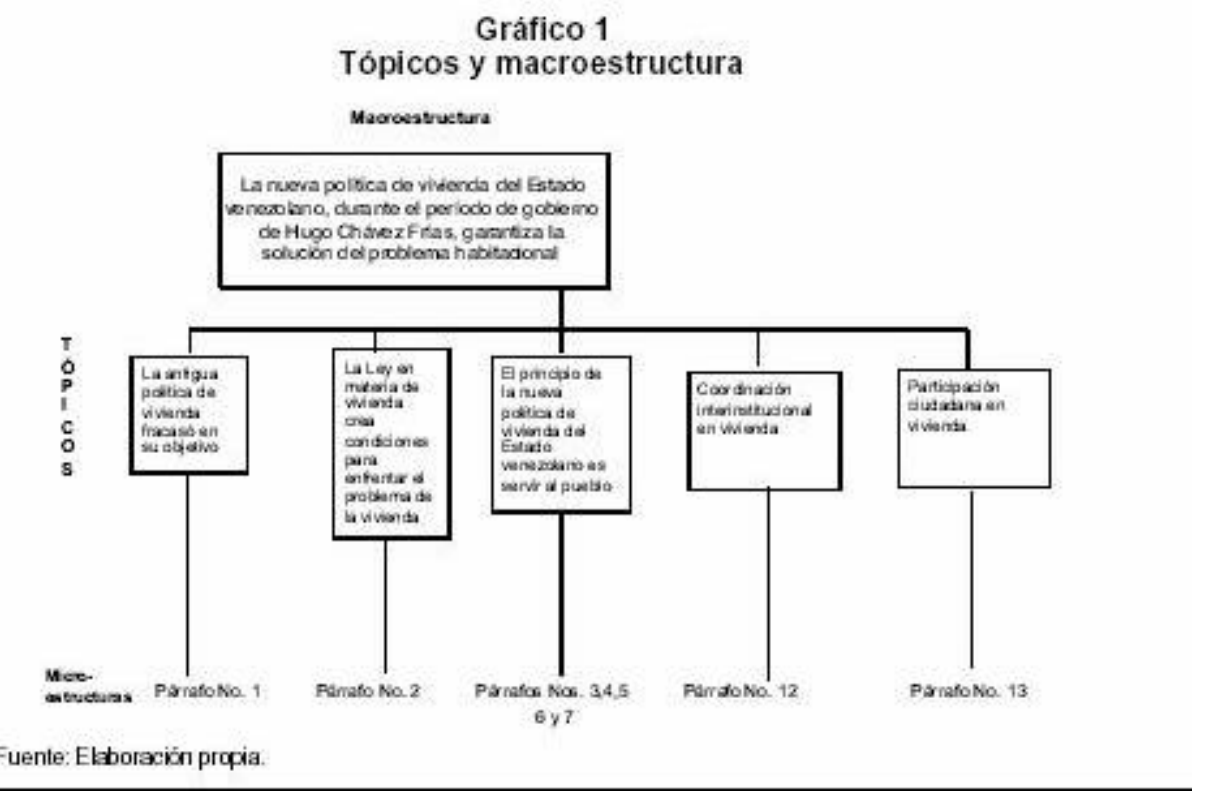

En el gráfico referido a los tópicos y macroestructura también se observa claramente que con el tópico de la nueva política de vivienda estamos en presencia de un proceso de mejoramiento, pues el discurso institucional construido por el nuevo gobierno encabezado por Hugo Chávez Frías en relación con esta problem ática, va desde la situación o realidad encontrada presentada como un proceso de degradación (vieja política de vivienda, negativas condiciones de vida de la población de bajos recursos, etc.), hasta una nueva realidad que se plantea como posible. Realidad que el sujeto "Estado venezolano" se propone cambiar a través de la puesta en práctica de una serie de acciones que constituyan, en síntesis, la nueva política habitacional del gobierno. Las acciones que en su conjunto plantea y que pueden conducir al cambio perseguido son: la ley de política habitacional que establece $5 \%$ de inversión en materia de vivienda, la coordinación interinstitucional, la participación ciudadana, el principio de solidaridad del nuevo Estado venezolano y un nuevo compromiso con los compatriotas de bajos recursos económicos.

\section{3. Nivel lógico conceptual: Los actores sociales en la política de vivienda}

Este nivel se da a partir de lo referencial y permite al analista reconstruir los esquemas cognitivos subyacentes en el discurso. Para Molero (1998) el proceso de conceptualización incluye la transformación de las percepciones e imaginaciones en signos lingüísticos. La autora considera el acto de representación mental importante, por ser la base de elección semiológica que utilizará el emisor para construir su mensaje. Esto se da una vez que el emisor elige el aspecto de la realidad que quiere comunicar.

Esto significa, en consecuencia, que el nivel conceptual tiene que ver con el propósito o 
la intención de comunicación del emisor del mensaje. El propósito de la comunicación lo relaciona, por tanto, con los otros actores, con aquellos que van actuar como receptores del mensaje. Estos receptores mediante su competencia lingüística y sus saberes identifican los elementos del mensaje y le dan sentido de modo que les permita comprenderlo y reaccionar en forma adecuada.

\section{Cuadro 1}

Temas o tópicos del documento analizado

\begin{tabular}{|c|c|c|}
\hline Pärrafo & Microestructuras & Tópico \\
\hline 1 & $\begin{array}{l}\text { - Las antiguas pol iticas de vivienda del Estado venezolano inten- } \\
\text { taron superar el déficit habitacional. } \\
\text { - Las antiguas politicas de vivienda del Estado venezolano esta- } \\
\text { ben destinadas ala poblaciónde escascs recursos económicos } \\
\text { - Las antiguas politicas de vivienda del Estado venezolano no la } \\
\text { graron su objetivo. } \\
\text { - Las antiguas politicas de vivienda del Estado venezolano se } \\
\text { ocuparon de las capas medias inferiores en la estratificación de } \\
\text { ingresos. } \\
\text { - Con la antigua politica de vivienda del Estado venezolano, la } \\
\text { mayoria de la población urbana se vio obligada a construir los } \\
\text { berrios de ranchos, donde actualmente viven casi } 13 \text { millones } \\
\text { de Dersanas. }\end{array}$ & $\begin{array}{l}\text { La antigua política } \\
\text { de vivienda fraca } \\
\text { só en su objetivo } \\
\text { de atención a la } \\
\text { población de be } \\
\text { jos recursos eco- } \\
\text { nómicos. }\end{array}$ \\
\hline 2 & $\begin{array}{l}\text { - Actualmente, el Estado cuenta con nuevas condiciones para } \\
\text { enfrentar exitosamente el problema de la vivienda. } \\
\text { - La ley obliga a invertir el } 5 \% \text { del presupuesto ordinario en la } \\
\text { atención de los actores tradicionalmente a bandonados. } \\
\text { - Más del } 90 \% \text { de la población (hoy) no puede tener acceso a la } \\
\text { vivienda por sus propics... medics. }\end{array}$ & $\begin{array}{l}\text { La ley en materia } \\
\text { de vivienda crea } \\
\text { condiciones para } \\
\text { enfrentar exitosa } \\
\text { mente el problema } \\
\text { de vivienda. }\end{array}$ \\
\hline $\begin{array}{c}3,4,5 \\
6 \text { y } 7\end{array}$ & $\begin{array}{l}\text { - El propósito del Estado es saldar la deuda social con los com- } \\
\text { patrictas de bajos ingresos que, históricamente, no han tenido } \\
\text { otro recurso que irvadirterrenospara crear barrios de ranchos. } \\
\text { - El principio que orienta la nueva politica de vivienda es servir al } \\
\text { pueblo, atendiendo sus negativas oondiciones urbanas de vida, } \\
\text { homdagándolas con las del resto de bs venezolanos. }\end{array}$ & $\begin{array}{l}\text { El principio de la } \\
\text { nueva politica de } \\
\text { vivienda del Esta- } \\
\text { do venezolano es } \\
\text { servir al pueblo. }\end{array}$ \\
\hline 12 & $\begin{array}{l}\text { - Para el logro de los objetivos de la politica nacional de vivienda } \\
\text { el Estado coordinara a sus organismos ejecutores oentrales: } \\
\text { INAVI, FONDUR, FUNDABARRIOS, VIVIENDA RURAL Y } \\
\text { FUNDACOMUN. } \\
\text { - EI Estado venezolano utilizará los institutos regionales y munici- } \\
\text { pales de vivienda para el logro de sus objetivcs. } \\
\text { - Todos los organismos públicos de vivienda serän coordinados } \\
\text { por el nuevo Consejo Nacional de la Vivienda (CONAVI) adscri- } \\
\text { to al Ministerio de Infraestructura. }\end{array}$ & $\begin{array}{l}\text { Coordinación inte } \\
\text { rinstitucional en } \\
\text { materia de vivien- } \\
\text { da. }\end{array}$ \\
\hline 13 & $\begin{array}{l}\text { - El problema de la vivienda presenta una complejidad y hetera. } \\
\text { geneidad que requiere del concurso de todos los venezolanos } \\
\text { para su solución. } \\
\text { - Los organismos públicos de vivienda deberán actuar como faci- } \\
\text { litadores de la actividad de todos los actores capaces de con- } \\
\text { currir con sus propios intereses y modos de actuar en la solu- } \\
\text { ción del problema de vivienda. }\end{array}$ & $\begin{array}{l}\text { Participación cilu } \\
\text { dadana en materia } \\
\text { de vivienda. }\end{array}$ \\
\hline
\end{tabular}

Fuente: Elaboración propia.

En los cuadros del análisis actancial (actores sociales) donde se recogen los párrafos que van desde el No. 1 hasta el 13, se observa que el gobierno nacional fundamentalmente plantea que el cambio es posible, que se puede generar una ruptura con la situación vigente referida al problema de la vivienda, es decir que se puede producir una nueva 
situación o evento. En dichos cuadros se observan las posiciones actanciales que configuran las tres zonas definidas en la teoría semántica (Pottier, 1993): la zona de la anterioridad contiene las causas de los diferentes eventos presentados en los tópicos; la zona del evento o del nudo principal presenta al agente dotado de potencia semántica, capaz de generar cambios y transformaciones en el paciente y en el destinatario; éste último, conjuntamente con la finalidad conforman la zona de la posterioridad. En esta zona (Cuadros 2 al 6 ), se observa que la finalidad tanto de la antigua política como de la nueva es solucionar el problema de vivienda, es decir superar el déficit de vivienda o mejorar las condiciones de vida urbana, cuyo destinatario es la población de bajos recursos económicos, aquéllos que no pueden tener acceso a una vivienda por sus propios medios.

\begin{tabular}{|c|c|c|c|c|c|}
\hline \multicolumn{6}{|c|}{$\begin{array}{l}\text { Cuadro } 2 \\
\text { Análisis actancial: La antigua politica }\end{array}$} \\
\hline \multicolumn{2}{|c|}{ Zona de la anterioridad } & \multicolumn{2}{|c|}{ Zona del evento } & \multicolumn{2}{|c|}{ Zona de la posterioridad } \\
\hline Tema & Causa & Agente & Paciente & Destinatario & Finalidad \\
\hline $\begin{array}{l}\text { Antigua } \\
\text { politica } \\
\text { pública de } \\
\text { vivienda }\end{array}$ & $\begin{array}{l}\text { Déficit de } \\
\text { viviendas }\end{array}$ & $\begin{array}{l}\text { Estado } \\
\text { venezdano }\end{array}$ & $\begin{array}{l}\text { Capas medias } \\
\text { inferiore } \\
\text { (estratificación } \\
\text { de ingresos) }\end{array}$ & $\begin{array}{l}\text { Población } \\
\text { de escasos } \\
\text { recursos } \\
\text { económicos }\end{array}$ & $\begin{array}{l}\text { Superar el } \\
\text { déficit de } \\
\text { viviendas }\end{array}$ \\
\hline
\end{tabular}

Fuenter Elaboración propia.

Cuadro 3

Análisis actancial: La nueva Ley

\begin{tabular}{|c|c|c|c|c|c|}
\hline \multicolumn{2}{|c|}{ Zona de la anterioridad } & \multicolumn{2}{|c|}{ Zona del evento } & \multicolumn{2}{|c|}{ Zona de la posterioridad } \\
\hline Tema & Causa & Agente & Paciente & $\begin{array}{l}\text { Destinatario } \\
\text { (beneficiario) }\end{array}$ & Finalidad \\
\hline $\begin{array}{l}\text { La nueva Ley } \\
\text { de vivienda }\end{array}$ & $\begin{array}{l}\text { Problema de la } \\
\text { vivienda }\end{array}$ & $\begin{array}{l}\text { Estado } \\
\text { venezolano }\end{array}$ & & $\begin{array}{l}90 \% \text { de la pa } \\
\text { blación que no } \\
\text { puede tener ao } \\
\text { ceso por sus } \\
\text { propios medios } \\
\text { a la vivienda }\end{array}$ & $\begin{array}{l}\text { Crear nuevas } \\
\text { condiciones } \\
\text { para enfrentar } \\
\text { con exito el } \\
\text { problema de } \\
\text { la vivienda }\end{array}$ \\
\hline
\end{tabular}

Fuente: Ekboración propia.

Cuadro 4

Análisis actancial: La nueva política

Párrafo No. $3,4,5,6$ y 7

\begin{tabular}{|c|c|c|c|c|c|}
\hline \multicolumn{2}{|c|}{ Zona de la anterioridad } & \multicolumn{2}{|c|}{ Zona del evento } & \multicolumn{2}{|c|}{ Zona de la posterioridad } \\
\hline Tema & Causa & Agente & Paciente & Destinatario & Finalidad \\
\hline $\begin{array}{l}\text { La nueva } \\
\text { politica de } \\
\text { vivienda }\end{array}$ & $\begin{array}{l}\text { Saldar la deuda } \\
\text { social con los } \\
\text { residentes de } \\
\text { barrios }\end{array}$ & $\begin{array}{l}\text { Estado } \\
\text { venezolano } \\
\text { (CONAVI) }\end{array}$ & & $\begin{array}{l}\text { Los competriotas } \\
\text { que irvaden terre } \\
\text { nos y construyen } \\
\text { barrios de ranchcs }\end{array}$ & $\begin{array}{l}\text { Mejorar las } \\
\text { condiciones } \\
\text { de vida urbana } \\
\text { del pueblo }\end{array}$ \\
\hline
\end{tabular}

Otros actores

Aliados:- Organizaciones comunitarias - Institucicnes publicas coordinadas

Oponentes: - Acbres beneliciados oxn invasiones Fuente: Ekboracićn propia 


\section{Cuadro 5}

Análisis actancial: La coordinación institucional

\begin{tabular}{|c|c|c|c|c|c|}
\hline \multicolumn{2}{|c|}{ Zona de la anterioridad } & \multicolumn{2}{|c|}{ Zona del evento } & \multicolumn{2}{|c|}{ Zona de la posterioridad } \\
\hline Tema & Causa & Agente & Paciente & Destinatario & Finalidad \\
\hline $\begin{array}{l}\text { Coordinación } \\
\text { interinstitucional }\end{array}$ & $\begin{array}{l}\text { Ausencia de } \\
\text { coordinación }\end{array}$ & $\begin{array}{l}\text { CONAVI (Estado } \\
\text { venezolano) }\end{array}$ & & $\begin{array}{l}\text { Personas con } \\
\text { dificultades } \\
\text { para adquirir } \\
\text { una vivienda }\end{array}$ & $\begin{array}{l}\text { Logro de los } \\
\text { objetivos de la } \\
\text { politica de vi } \\
\text { vienda }\end{array}$ \\
\hline
\end{tabular}

Otros actores

Auxiliares: -Nueva politica nacicnal de viwienda

Aliados:- Nuevo Estado venezdano Oponentes:- Burocracia

Fuente: Elaboración propia.

Cuadro 6

Análisis actancial: La participación ciudadana

\begin{tabular}{|c|c|c|c|c|c|}
\hline \multicolumn{2}{|c|}{ Zona de la anterioridad } & \multicolumn{2}{|c|}{ Zona del evento } & \multicolumn{2}{|c|}{ Zona de la posterioridad } \\
\hline Tema & Causa & Agente & Paciente & Destinatario & Finalidad \\
\hline $\begin{array}{l}\text { Participación } \\
\text { ciudadana en } \\
\text { materia de } \\
\text { vivienda }\end{array}$ & $\begin{array}{l}\text { Complejidad y he } \\
\text { terogeneidad del } \\
\text { problema de la vi- } \\
\text { vienda }\end{array}$ & $\begin{array}{l}\text { Organismce } \\
\text { públicos de } \\
\text { vivienda } \\
\text { (Estado } \\
\text { venezclano) }\end{array}$ & $\begin{array}{l}\text { Organismos } \\
\text { pủblicos, em- } \\
\text { presas priva- } \\
\text { das, ONG, co- } \\
\text { munidades or- } \\
\text { ganizadas }\end{array}$ & $\begin{array}{l}\text { Personascon } \\
\text { dificultades } \\
\text { para adquirir } \\
\text { viviendas }\end{array}$ & $\begin{array}{l}\text { Solución del } \\
\text { problema de } \\
\text { la vivienda }\end{array}$ \\
\hline \multicolumn{6}{|c|}{$\begin{array}{l}\text { Otros actores } \\
\text { Auxiliares: Nuava politica nacicna de vi } \\
\text { Aliados:-Organizacicnes comunitarias } \\
\text { - Nuawo Estado venezolaro } \\
\text { Fuente: Elaboraciñ procia. }\end{array}$} \\
\hline
\end{tabular}

Por otra parte, en la zona del evento se descubre que el único agente social que puede impulsar el cambio de la situación es el Estado mismo, él cual en el documento analizado se autocalifica como el "nuevo Estado venezolano". El discurso analizado revela que el cambio es posible en el paciente y en el destinatario, receptores de los efectos negativos de la antigua política y posibles beneficiarios de la nueva política propuesta.

Para el emisor institucional el logro del cambio implica, en consecuencia, que se actúe sobre los factores causales del fracaso de la vieja política de vivienda, tales como: la ausencia de coordinación interinstitucional, la falta de participación ciudadana y la falta de compromiso del Estado con la población objetivo, en términos de Sulbrandt (1983).

El hecho de plantearse el cambio en el discurso institucional, significa que éste se construye alrededor del concepto de proceso, concebido como “...un conjunto de fenómenos consecutivos, progresivos, una cadena de acontecimientos..." (Molero, 1985:91). En la realidad construida en el discurso se maneja temporalmente el pasado, el presente y el futuro. El pasado lo asocia a la vieja política de vivienda, representa la degradación de la realidad experimentada por la población de bajos recursos económicos; 
el presente lo asocia a la nueva política que se corresponde con el nuevo Estado venezolano, el cual se representa así mismo -el gobierno de Hugo Chávez Frías- como portador del proceso de mejoramiento, como el agente de cambio y el futuro lo vincula a la nueva realidad institucional y social que emergerá de la aplicación de la nueva política. El análisis actancial permitirá identificar las causas, las finalidades y los actores de los procesos de degradación y de mejoramiento que intenta explicar el documento analizado.

\subsection{Nivel lingüístico}

En este nivel el emisor elige los signos de la lengua para expresar el propósito ya conceptualizado, disponiendo de los recursos léxicos a través de los cuales comunica su propósito.

En el caso del discurso institucional analizado, se observan en el Cuadro 7 los términos correspondientes a cada uno de los diferentes tópicos contenidos en la representación semántica o macroestructura. El léxico es importante porque coadyuva en la identificación de la estructura ideacional o mapa conceptual contenido en el discurso. La observación del léxico permitirá establecer cuál de los tópicos es valorado positivamente y cuál o cuáles son valorados negativamente, de acuerdo con los efectos de sentido que el emisor intente causar en el receptor del mensaje.

En general, en cuatro de los cinco tópicos se observan campos lexicales positivos. El negativo tiene que ver con el tópico referido a la antigua política de vivienda. Investigaciones anteriores, especialmente en el ámbito del discurso político (Molero, 1985, 1999, 2002), señalan que cuando se trata de presentar procesos de mejoramiento el estado inicial del evento, por lo general, se califica en forma negativa. Y, por supuesto, los restantes se califican en forma positiva por estar más relacionados con el estado final del proceso o de las acciones. En el nivel anterior del análisis, hemos podido constatar que el estadio inicial del problema de la vivienda está representado mediante un proceso de degradación y que las fases ulteriores correspondientes a diferentes estadios de la transformación son asumidas en forma positiva como proceso de mejoramiento. Observemos la valoración positiva y negativa a través del léxico en el Cuadro 7.

La aproximación al nivel lexical indica que en el discurso subyace un esquema binario constituido por un eje negativo y un eje positivo. El léxico se muestra coherente con la conceptualización y el análisis actancial del nivel anterior. 


\begin{tabular}{|c|c|c|c|}
\hline \multicolumn{4}{|c|}{$\begin{array}{c}\text { Cuadro } 7 \\
\text { Tópicos y léxico }\end{array}$} \\
\hline Párrafos & Tópicos & Léxico & $\begin{array}{c}\text { Efectos } \\
\text { de sentido }\end{array}$ \\
\hline 1 & $\begin{array}{l}\text { Antigua politica } \\
\text { de vivienda }\end{array}$ & $\begin{array}{l}\text { - Estado venezolano, } \\
\text { - déficit habitacional, } \\
\text { - población de escasos recursos económiccs, } \\
\text { - capas medias inferiores, } \\
\text { - estratificación de ingresos, } \\
\text { - población urbana, } \\
\text { - obligó a la construcción de barrios de ranchos, } \\
\text { - sin lograr objetivos }\end{array}$ & Negativo (-) \\
\hline 2 & $\begin{array}{l}\text { La nueva Ley } \\
\text { de vivienda }\end{array}$ & $\begin{array}{l}\text { - Estado, } \\
\text { - nuevas condiciones, } \\
\text { - problema de vivienda, } \\
\text { - inversión, } \\
\text { - presupuesto ordinario, } \\
\text { - atención a sectores sociales } \\
\text { tradicionalmente preteridos } \\
\text { - acceso a vivienda }\end{array}$ & Positivo (+) \\
\hline $3,4,5,6,7$ & $\begin{array}{l}\text { Nueva politica } \\
\text { de vivienda }\end{array}$ & $\begin{array}{l}\text { - trata de saldar la deuda social } \\
\text { - atención a los compatriotas de bajos ingresces, } \\
\text { - principio orientador: servir al pueblo, } \\
\text { - mejorar condiciones urbanas de vida, } \\
\text { - homologación de condiciones entre los } \\
\text { venezolancs } \\
\text { - rectificar el papel del Estado }\end{array}$ & Positivo ( +) \\
\hline 12 & $\begin{array}{l}\text { Coordinación } \\
\text { interinstitucional }\end{array}$ & $\begin{array}{l}\text { - Logro de objetivos, } \\
\text { - politica nacional de vivienda, } \\
\text { - Estado, } \\
\text { - coordinación, } \\
\text { - organismos ejecutores centrales, } \\
\text { - institutos regionales y municipalas, } \\
\text { - Consejo Nacional de Vivienda }\end{array}$ & Positivo (+) \\
\hline 13 & $\begin{array}{l}\text { Participación } \\
\text { ciudadana en } \\
\text { materia de } \\
\text { vivienda }\end{array}$ & $\begin{array}{l}\text { - Problema de vivienda, } \\
\text { - complejidad, heterogeneidad, } \\
\text { - concurso de todos, } \\
\text { - organismos públicos facilitadores, } \\
\text { - actores, interés propio, } \\
\text { - solución del problema de la vivienda }\end{array}$ & Positivo (+) \\
\hline
\end{tabular}

Fuente: Ekboración propia.

\section{5. Contexto y discurso analizado}

Todo discurso es un acto lingüístico. Y un acto lingüístico es un acto “...mediante el cual el hablante se expresa en un lenguaje natural dentro de un tipo específico de situación comunicativa llamada también contexto" (Molero, 1985:33). En este sentido, el acto lingüístico “....no es solamente el acto de hablar sino que además es un acto social por medio del cual se produce la interacción de los miembros de una comunidad" (Molero, 1985:33). De allí que al ser un acto social puede cumplir la función básica de influir en la forma de pensar de un oyente, es decir, que el acto lingüístico como acción específica tiene una intencionalidad que le asigna el actor social que lo ejecuta, la cual esta influida por la situación vigente. Apelando a Ibáñez (1998), diremos que los actos sociales están 
determinados por las condiciones socioeconómicas, culturales, valores, etc., que caracterizan a la sociedad; por los mecanismos internos de construcción de los actos lingüísticos; por la práctica social del emisor y por la experiencia personal o institucional que éste tiene con el objeto al cual se refiere.

Entre los actos de habla encontramos: aseveraciones ("La política nacional de vivienda obedece a un principio de solidaridad y de justicia social"); y promesas ("En los próximos 5 años se atenderán las necesidades colectivas de 45.000 familias").

En el discurso analizado se encuentra que el emisor del mismo es una institución pública. Dada la naturaleza del emisor el evento comunicativo o tipo de discurso es políticoinstitucional y trata, como ya se anotó, sobre la política pública de vivienda.

El propósito que persigue el emisor con el discurso es informar (macroacto de habla) acerca de la nueva política de vivienda, al mismo tiempo que busca persuadir al receptor acerca de las cualidades positivas de las nuevas políticas gubernamentales, resaltando para ello su nivel de compromiso y solidaridad con la población de bajos recursos económicos. En ese sentido, la institución pública que emite el documento busca legitimarse, por lo menos formalmente, ante la población objetivo del discurso.

En el discurso analizado los receptores previstos son básicamente el conjunto de instituciones que componen el sector público social de la vivienda (receptores explícitos). El segmento social de la sociedad, cuya característica principal es tener bajos recursos económicos, es quien recibirá los bienes y servicios contemplados en la política pública y los programas sociales de vivienda, y se define, en términos de Sulbrandt (1983) como población objetivo o destinataria de dicha política.

El tipo de evento comunicativo tiene como resultado un documento escrito sobre la situación de la vivienda en Venezuela y la nueva política nacional de vivienda. Dicho documento, como discurso institucional, se produce en Venezuela y es enunciado en el año 2000. Para esa fecha en particular, el país experimentaba una profunda dinámica de cambios políticos, sociales y económicos. Los cambios estaban determinados por la emergencia de una nueva mayoría política instalada en el ejercicio del poder político y por la expresión y demanda manifiesta de la población (elecciones presidenciales y de gobernadores, etc.) de medidas políticas novedosas vinculadas a los intereses de la población que históricamente ha permanecido al margen de los beneficios de la política pública del Estado venezolano.

Las demandas de cambios manifestadas en el país, como realidad construida, conduce a 
afirmar que el discurso institucional elaborado por el gobierno de Hugo Chávez Frías, resulta apropiado, adecuado y oportuno para el momento que estaba viviendo la sociedad venezolana. Por tal motivo, siguiendo a Van Dijk (1998) puede decirse que el sentido transmitido por el discurso estaba en concordancia con el contexto.

\subsection{Modo de organización discursivo}

En el documento sobre la nueva política de vivienda se observa que el modo de organización predominante es el argumentativo. De acuerdo con Charaudeau (1992: 789) la relación argumentativa se basa en tres tipos de aserciones: una aserción de partida (datos, premisas) configurada como un enunciado que hace posible que otra aserción sea admitida; una aserción de llegada que representa lo que debe ser aceptado, en vista de la relación de causalidad que se establece con la aserción de partida y una aserción de pasaje que justifica la relación de causalidad entre la aserción de partida y la de llegada. De acuerdo con estas premisas teóricas el esquema de organización discursiva del texto analizado descansa fundamentalmente en una relación argumentativa, tal como puede observarse en el Cuadro 8.

\begin{tabular}{|c|c|c|}
\hline \multicolumn{3}{|c|}{$\begin{array}{l}\text { Cuadro } 8 \\
\text { La relación argumentativa }\end{array}$} \\
\hline Aserciōn de Partida & Aserción de Pasaje & Aserción de Llegada \\
\hline $\begin{array}{l}\text { Las antiguas politicas de vivien- } \\
\text { da del Estado venezolano in- } \\
\text { tentaron superar el déficit habi- } \\
\text { tacional... sin lograr su objetivo }\end{array}$ & $\begin{array}{l}\text { Pruebas: } \\
\text { - Obligaron a la población a } \\
\text { construir barrios de ranchos } \\
\text { - Casi } 13 \text { millones de personas } \\
\text { viven en ranchos } \\
\text { - No se sabldó la deuda social }\end{array}$ & $\begin{array}{l}\text { En consecuencia es necesaria: } \\
\text { Una nueva politica de vivienda } \\
\text { que atienda las negativas con- } \\
\text { diciones urbanas existentes }\end{array}$ \\
\hline
\end{tabular}

El documento objeto de estudio responde, dentro del esquema argumentativo, a uno de los procedimientos discursivos de éste último, el cual se utiliza para producir efectos de persuasión. Se trata de la comparación, que en el discurso se construye mediante la utilización de dos categorías de lengua: A) la calificación que se manifiesta en las propiedades que se atribuyen a las dos políticas de vivienda contrapuestas, a fin de que el receptor-destinatario aprecie la disparidad entre ambas. Por supuesto, en la construcción de la imagen de cada política se utiliza la calificación negativa para la antigua política como ya se ha constatado en otros niveles del análisis - y la positiva para la nueva política. B) la cuantificación se emplea especialmente para caracterizar las metas de la nueva política. Se menciona por ejemplo, la cantidad de empleos que generará ("100.000 empleos estables"), las familias que atenderá ("400.000 familias en 5 años") y la cantidad de viviendas que se construirán ("90.000 viviendas en 5 años"). 
Si observamos la antigua política de vivienda descubriremos que el tipo de operación que se utiliza para cuantificar es la que se conoce como nula (Charaudeau, 1992: 243): "Las antiguas políticas de vivienda del Estado venezolano intentaron superar el déficit habitacional... sin lograr su objetivo".

Tanto la cuantificación como la calificación hacen posible la construcción de dos imágenes de políticas de vivienda que son dispares y que se oponen tanto en su concepción como en sus objetivos. La estrategia de comparación cumple la finalidad discursiva de deslegitimar la política de vivienda del estado venezolano en el pasado, intentando al mismo tiempo legitimar la nueva política gubernamental.

Otro aspecto interesante en la organización del discurso se basa en los tres ejes temporales que recuerdan -aunque vagamente- una de las características del modo de organización narrativo. El eje temporal pasado alude al "otro", es decir a los gobiernos anteriores; el eje temporal del presente representa el "nosotros", es decir los artífices de la nueva política de vivienda y el gobierno que la implementará; el eje del futuro es el eje promisorio: "Atenderá y mejorará estructuralmente las condiciones colectivas de urbanización de un millón de personas en el plazo de 5 años".

\subsection{Estrategias discursivas}

En el Cuadro 9 referido a las estrategias se observa que el emisor en la construcción del discurso emplea varias estrategias. En primer lugar se anota la estrategia de comparación entre la vieja y nueva política pública de vivienda, que como se señaló cumple un cometido en el marco de la argumentación. 
Cuadro 9

Estrategias discursivas

\begin{tabular}{|c|c|c|}
\hline Estrategias & Construcción & Recursos \\
\hline Comparación & $\begin{array}{l}\text { Compera la actuación de la } \\
\text { vieja politica de vivienda con la } \\
\text { nueva politica }\end{array}$ & $\begin{array}{l}\text { Dramatiza la negativa actua } \\
\text { ción del Estado en el pasado }\end{array}$ \\
\hline $\begin{array}{l}\text { Victimización de las familias de } \\
\text { bajos recursos económicos } \\
\text { (perspectiva de la antigua } \\
\text { política) }\end{array}$ & $\begin{array}{l}\text { Las familias de bajce ingresos } \\
\text { fueron obligodas a construir y a } \\
\text { vivir en barrios de rancho }\end{array}$ & $\begin{array}{l}\text { Representa las negativas con } \\
\text { diciones de vida de las familias } \\
\text { de bajos ingresos }\end{array}$ \\
\hline $\begin{array}{l}\text { Solidaridad/cercania } \\
\text { (perspectiva de la nueva } \\
\text { politica) }\end{array}$ & $\begin{array}{l}\text { La politica nacional de vivien- } \\
\text { da obedece a un principio de } \\
\text { solidaridad y de justicia social }\end{array}$ & $\begin{array}{l}\text { Seidentifica conlas familias de } \\
\text { bajos ingrescs } \\
\text { "Compatriotas': dencminación } \\
\text { de los beneficiarios }\end{array}$ \\
\hline $\begin{array}{l}\text { Compromiso } \\
\text { (perspectiva de la nueva } \\
\text { politica) }\end{array}$ & $\begin{array}{l}\text { Rechaza las condiciones de } \\
\text { vida de la población de bajos } \\
\text { ingresos } \\
\text { Reafirma la concepción de las } \\
\text { politicas públicas al servicio de } \\
\text { la población }\end{array}$ & Deber del Estado \\
\hline
\end{tabular}

Fuente: Elaboración propia.

También emplea la estrategia de victimización con respecto a las familias de menores ingresos a quienes se obligó construir y a vivir en barrios de ranchos, bajo el esquema de la antigua política. Esto, por supuesto, lo conduce a afirmar al mismo tiempo, que la vieja política representa las negativas condiciones de vida de esas familias. Existe desde esta perspectiva la construcción de una doble imagen de los grupos destinatarios de las políticas públicas de vivienda del Estado venezolano. Bajo la antigua política los destinatarios ("capas medias inferiores") se perciben como víctimas y bajo la nueva política se conciben como beneficiarios. De allí que el emisor del discurso pasa de la estrategia de victimización a la estrategia de solidaridad y cercanía, cuando representa la nueva política como la única capaz de generar una transformación de la realidad existente en materia de vivienda, entre la población de menores ingresos económicos. Se revela entonces la intención del emisor-institucional de crear una pararrealidad discursiva entendida como una "referencia presente-descripta en un discurso" (Raiter, 1999: 98) que responde al proceso de cambio radical y transformaciones que prometió en sus discursos desde la campaña electoral el presidente Hugo Chávez. Esto indica además, que un discurso institucional como el analizado, no puede estudiarse aislado porque él forma parte de una red que se teje en un determinado contexto social, político, económico. La realidad discursiva creada por el discurso político del presidente, según la cual los destinatarios en 1998 dedujeron la necesidad de un cambio, ha incidido decisivamente en el discurso institucional de su gobierno, de manera que los ejes temporales, las relaciones argumentativas y hasta las estrategias discursivas en el texto analizado son tributarias del discurso político.

El emisor del discurso (una institución gubernamental) asume esta última estrategia de 
solidaridad como suya. Es decir, establece una asociación entre el nuevo gobierno nacional y la solidaridad y cercanía con los destinatarios o beneficiarios de la política de vivienda. Pues, él la vincula a la identificación que se establece con las familias de bajos ingresos, lo cual significa que rechaza los resultados hasta el momento obtenidos con las políticas públicas de vivienda.

Este rechazo explica el porqué el emisor hace uso también de la estrategia del compromiso, la cual es asociada al deber que el Estado venezolano tiene con el mejoramiento de las condiciones de vida de la población de bajos recursos económicos.

\section{Conclusiones}

El contexto en el que se origina el documento emanado del Consejo Nacional de la Vivienda señala que, a pesar de que en Venezuela el Estado venezolano ha diseñado e instrumentado políticas públicas de vivienda, la problemática de la vivienda continúa en ascenso. El discurso institucional se ha construido partiendo del mundo referencial encontrado, pero en él se construye la imagen de una realidad discursiva en torno a la cual se teje una argumentación. Allí se habla de un viejo y de un nuevo Estado venezolano y de sus respectivas políticas en materia de vivienda.

El discurso analizado es coherente debido a que los diferentes tópicos que lo componen se corresponden con la macroestructura del discurso. Y desde el punto de vista pragmático se percibe apropiado, adecuado y oportuno en relación con el contexto sociopolítico en el cual hace su aparición.

El análisis actancial reveló las causas, finalidades, agentes y pacientes de los diferentes tópicos. En el nivel lingüístico, la observación del léxico hizo posible obtener los efectos de sentido que buscaba el emisor en la valoración positiva o negativa de cada tópico. Los valores positivos fueron asociados a la nueva política pública de vivienda inherente al gobierno y los negativos a la vieja política perteneciente a los gobiernos anteriores. En los lugares simbólicos de la enunciación, a pesar de que la nueva política de vivienda se manifiesta en tercera persona del singular, se advierte que subyace en ella el "nosotros", es decir los artífices de la política y el gobierno que la pondrá en ejecución. El "otro" se refiere a los gobiernos anteriores, que en el contexto político corresponde a los oponentes.

El propósito del discurso es informar la nueva política pública de vivienda, al mismo tiempo que persuadir a los receptores de las cualidades de la misma. Es decir, que se observa una cercanía en cuanto a recursos lingüísticos y estrategias discursivas entre el discurso político actual y el discurso institucional de las entidades gubernamentales, 
dejando a salvo - claro está- que la finalidad del primero busca persuadir al receptor para obtener o mantener el poder, mientras que el segundo trata de sustentar y dar a conocer las políticas públicas.

El discurso analizado posee la misma estructura lógico-conceptual de los mensajes del presidente de la República, desde la época de la campaña electoral; esa estructura en forma resumida puede enunciarse así: hubo en el pasado en el país, un estado de cosas negativas que es necesario cambiar radicalmente hacia un estado calificado como positivo. Si en el discurso político el único agente capaz de lograr esta transformación es el líder, en el caso del discurso institucional el agente es un nuevo estado con las políticas del nuevo gobierno. De manera que el agente benefactor se desplaza desde un actante humano (discurso político) hasta un actante institucional (discurso institucional), a lo cual se agrega que el comportamiento asumido por ambos es el mismo: poseen suficiente potencia semántica para emprender por sí solos cambios que transformen la realidad del paciente beneficiario (el pueblo). Además, el análisis actancial mostró el marco en el cual actúan los agentes: las causas, finalidades, actores aliados y oponentes, tanto en la antigua política de vivienda, como en la nueva.

Por otra parte, en el discurso institucional se advierten también dos de las funciones estratégicas básicas del discurso político: las funciones de legitimación y deslegitimación. La primera corresponde a la nueva política y la segunda a la política de gobiernos anteriores.

El discurso se basa en un esquema que contrapone lo viejo (los cuarenta años del bipartidismo) y lo nuevo (el gobierno electo en 1998), con lo cual se constata que el discurso político del presidente Hugo Chávez Frías ha ofrecido las pautas seguidas en los discursos institucionales del Estado venezolano, desde su llegada al poder.

* Este artículo corresponde a los resultados de la investigación "Política de Vivienda y Modelos de Desarrollo en Venezuela", auspiciada por el Consejo de Desarrollo Científico y Humanístico (CONDES), y adscrita al Centro de Estudios de la Empresa de la Facultad de Ciencias Económicas y Sociales de la Universidad del Zulia. Y es el trabajo final del Seminario "Análisis del Discurso", coordinado por los Dres. Lourdes Molero de Cabeza y Julián Cabeza, cursado en el Doctorado de Ciencias Sociales, convenio UCV-LUZ, primer periodo de 2001.

1. El documento contiene la nueva política de vivienda: la concepción de vivienda, una descripción de los programas: Atención a las poblaciones de las calles, Habilitación Física de las zonas de barrios, Mejoramiento y ampliación de casas en barrios, Rehabilitación de urbanizaciones populares, Nuevas urbanizaciones y viviendas 
de desarrollo progresivo, Nuevas urbanizaciones y viviendas regulares; contiene además los efectos del programa en el empleo y el rol del programa Bolívar 2000.

\section{Referencias Bibliográficas}

1. CONZUPLAN, Departamento de Asesoría de población y Vivienda (2000), Balance de necesidades y déficit de vivienda. Maracaibo, Venezuela.

2. Charaudeau, Patrick (1992), Grammaire du sens et de l'expression, París, Hachette.

3. Ibáñez, Tomás (1998), Psicología social construccionista. México, Universidad de México.

4. Molero de C., Lourdes (1985), Lingüística y discurso. Venezuela, Universidad del Zulia, Ediciones Facultad Experimental de Ciencias.

5. Molero de C., Lourdes (1998), Un modelo lingüístico para la planificación de la enseñanza de la lengua materna. En Enseñanza de la lengua materna. Teoría y práctica, Venezuela, Ediciones Fundacite Zulia, pp. 11-39.

6. Molero de C., Lourdes (1999), Análisis de dos discursos del proceso electoral de 1998 bajo un enfoque semántico pragmático. En Bolívar y Kohn (comp.) El discurso político venezolano. Un estudio multidisciplinario, Venezuela, Ediciones Comisión de Estudios de Postgrado UCV y Fondo Editorial Tropikos, pp. 145-157.

7. Molero de C., Lourdes (2001), Formas y estrategias de persuasión en el discurso político venezolano. La construcción del "yo" y del "otro" bajo un enfoque sem ántico y pragmático, Discurso y Sociedad, Vol. 3 (4), España, Editorial Gedisa, pp. 11 33.

8. Molero de C., Lourdes (2002), El personalismo en el discurso político venezolano. Un enfoque semántico y pragmático. Coedición Convergencia Año 9, No. 28, México, Universidad Autónoma del Estado de México y Espacio Abierto Vol. 11, No. 2, Venezuela, Universidad del Zulia, pp. 291-334.

9. Pottier, Bernard (1993), Semántica general, Madrid, Gredos.

10. Raiter, Alejandro (1999), Lingüística y política. Argentina, Editorial Biblos. 
11. Sulbrandt, José (1983), Evaluación del Impacto Social de la Acción de las Empresas Públicas. Revista Venezolana de Desarrollo Administrativo, No. 4, Venezuela, Fundaciones Fundacademus, pp. 83-111.

12. Van Dijk, Teun (1998), Estructura y funciones del discurso, España, Editores Siglo XXI.

13. Van Dijk, Teun (1999), Ideología. Una aproximación multidisciplinaria, España, Editorial Gedisa. 